\title{
Standar Kecantikan Perempuan Berhijab dalam Iklan Televisi (Analisa Semiotika Iklan Wardah Versi Feel The Beauty)
}

\author{
Christinawati, Ahmad Junaidi \\ Christinawati722@gmail.com,ahmadd@fikom.untar.ac.id
}

Fakultas Ilmu Komunikasi Universitas Tarumanagara

\begin{abstract}
This research is to provide knowledge and insight to the reader. This research is about the standard of hijab women's beauty in television commercials (Semiotic analysis to Wardah version of Feel The Beauty). The thing to be discussed is the message to be conveyed through the advertisement by asking Wardah. Received responses from Wardah users in Jakarta. The beauty standard of social media construction is television through advertisement shows. The theory used in this study, namely beauty, mass media, television advertising as mass communication and social construction of advertising in mass media. This research is a descriptive qualitative research, interpreting sign through semiotic analysis with Roland Barthes theory by using denotation, connotation and myth. Conduct interviews with Wardah and women who use Wardah products. The results showed that the woman's beauty standards not only from outside, including from within yourself. The women placed in the advertisements also seem to fit the message that they want to convey.
\end{abstract}

Keywords: advertisement, beauty, veil.

\begin{abstract}
Abstrak
Penelitian ini bertujuan untuk memberi pengetahuan dan wawasan kepada pembaca. Penelitian ini tentang standar kecantikan perempuan berhijab dalam iklan televisi (Analisis semiotika iklan Wardah versi Feel The Beauty). Hal yang ingin dibahas yaitu, pesan yang ingin disampaikan melalui iklan tersebut dengan bertanya kepada pihak Wardah. Mendapat tanggapan tentang iklan tersebut dari pengguna pihak Wardah yang berada di Jakarta. Adanya standar kecantikan dari konstruksi sosial media yaitu televisi melalui tayangan iklan. Teori yang dipakai dalam penelitian ini, yaitu kecantikan, media massa, iklan televisi sebagai komunikasi massa dan konstruksi sosial iklan dalam media massa. Penelitian ini merupakan penelitian kualitatif deskriptif, memaknai tanda melalui analisis semiotika dengan teori Roland Barthes dengan menggunakan denotasi, konotasi dan mitos. Melakukan wawancara mendalam dengan pihak Wardah dan perempuan yang menggunakan produk Wardah. Hasil penelitian menunjukkan bahwa standar kecantikan perempuan itu tidak hanya dari luar saja termasuk dari dalam diri. Perempuan yang berada di dalam iklan pun terlihat sesuai dengan pesan yang ingin disampaikan.
\end{abstract}

Kata Kunci : hijab, iklan, Kecantikan.

\section{Pendahuluan}

Di era sekarang perempuan dapat mengekspresikan diri dengan salah satu cara yaitu menggunakan makeup untuk meningkatkan kepercayaan diri dalam melakukan aktivitas seperti menghadiri beberapa acara formal maupun informal. Dalam masyarakat, kecantikan memiliki standar yang ditetapkan oleh masyarakat itu sendiri. Kepopuleran kecantikan tidak lepas dari pengaruh media massa, terutama media elektronik televisi yang mempunyai kekuatan audio visual melalui tayangan iklan 
produk kecantikan. Kecantikan adalah salah satu bentuk konstruksi media massa. Media massa merupakan sebuah alat komunikasi untuk menyampaikan informasi dan mempengaruhi khalayak.

Salah satu medianya yaitu iklan. Iklan merupakan sarana yang tepat untuk menawarkan berbagai produk salah satunya adalah produk kecantikan. Berdasarkan penelitian Wulan Purnama Sari dengan judul Konflik Budaya Dalam Konstruksi Kecantikan Wanita Indonesia (Analisis Semiotika dan Marxist Iklan Pond's White Beauty versi Gita Gutawa) iklan dibuat untuk mendorong orang agar menjadi konsumtif dengan menciptakan pemikiran kepada perempuan tentang kecantikan. Iklan mengkonstruksi masyarakat menjadi kelompok-kelompok gaya hidup, yang kehidupan mereka diatur berdasarkan berdasarkan tema, citra, dan makna simbolik tertentu. Jika diamati dalam tontonan massa tersebut gaya hidup yang dikonstruksikan antara lain tentang penampilan, kejantanan, maskulin, feminim dan juga kecantikan. Kecantikan perempuan menjadi Stereotype yang kemudian menjadi ide dan citra untuk pembuatan iklan. Salah satunya adalah iklan kosmetik dari Wardah. Wardah merupakan salah satu brand kosmetik lokal yang telah berdiri sejak 1995 dan memiliki peminat yang cukup tinggi di kalangan perempuan. Wardah mencitrakan dirinya sebagai produk kosmetik yang islami, hal ini dapat dilihat dari salah satu iklan yang melibatkan beberapa perempuan yang berhijab. Pada awalnya citra kosmetik Wardah di tunjukkan untuk perempuan muslim, namun perkembangan era kosmetik membuat Wardah dapat dinikmati oleh kalangan yang lebih luas.

Dalam iklan televisi kosmetik Wardah versi Wardah Feel the Beauty yang dikeluarkan pada tahun 2019 di bagian penutup, Wardah memberikan slogan "Bersama Wardah ada banyak inspirasi untuk pancarkan cantikmu yang sesungguhnya. Wardah Feel The Beauty". Kosmetik Wardah selalu menarik perhatian masyarakat karena selalu memberikan pesan di setiap iklannya. Hal ini membuat penulis tertarik untuk memberikan pandangan serta meneliti makna-makna dari iklan Kosmetik Wardah versi Wardah Feel The Beauty di media televisi. Tujuan dari penelitian adalah untuk memahami dan mengetahui standar kecantikan perempuan berhijab dan makna tanda dalam iklan kosmetik Wardah versi Feel Beauty.

\section{Metode Penelitian}

Dalam melakukan penelitian kualitatif, maka terdapat tiga jenis model desain penelitian kualitatif, yaitu format deskriptif, format verifikatif, format grounded research. Format deskriptif lebih tepat apabila digunakan untuk meneliti masalahmasalah yang membutuhkan studi mendalam, seperti permasalahan tingkah laku konsumen suatu produk, masalah-masalah efek media terhadap pandangan pemirsa terhadap suatu tayangan media, permasalahan implementasi kebijakan publik di masyarakat dan sebagainya. Data yang dikumpulkan dalam format deskriptif adalah berupa kata-kata, gambar, dan bukan angka-angka. Laporan penelitian akan berisi kutipan-kutipan data untuk memberi gambaran penyajian laporan. Data tersebut mungkin berasal dari naskah wawancara, catatan lapangan, foto, videotape, dokumen pribadi, catatan atau memo, dan dokumen resmi lainnya. Pertanyaan dengan kata tanya mengapa, alasan apa dan bagaimana terjadinya akan senantiasa dimanfaatkan oleh peneliti. 


\section{Hasil Temuan dan Diskusi}

Produk kecantikan merupakan produk yang dapat memenuhi kebutuhan perempuan akan kecantikan sekaligus menjadi sarana untuk memperjelas identitas dirinya di mata masyarakat. Banyak cara yang dapat digunakan perusahaan untuk memuaskan kebutuhan perempuan. Produk memang tidak dirancang untuk memenuhi kebutuhan fungsionalnya saja namun juga memenuhi kebutuhan sosial dan psikologi. Penulis akan membuat ringkasan temuan dari setiap adegan yang diakhiri dengan analisis deskriptif. Berdasarkan hasil penelitian, Wardah adalah sebuah produk kecantikan yang kurang lebih sudah 24 tahun berkembang di Indonesia. Produk ini menjadi pelengkap keseharian dalam merawat kulit sejak kosmetik Wardah pertama kali diluncurkan pada tahun 1995. Produk kecantikan ini selalu mengeluarkan inovasi baru. Tidak heran jika produk kecantikan ini selalu digemari oleh banyak perempuan. Pada awal tahun 2019, Wardah membuat iklan dengan tagline yang baru yaitu Feel The Beauty. Tagline sebelumnya yaitu Wardah Inspiring Beauty yang berubah menjadi Wardah Feel The Beauty. Iklan tersebut memberikan pesan tentang standar kecantikan untuk semua perempuan. Produk kecantikan sudah tidak asing lagi bagi perempuan terutama di Jakarta.

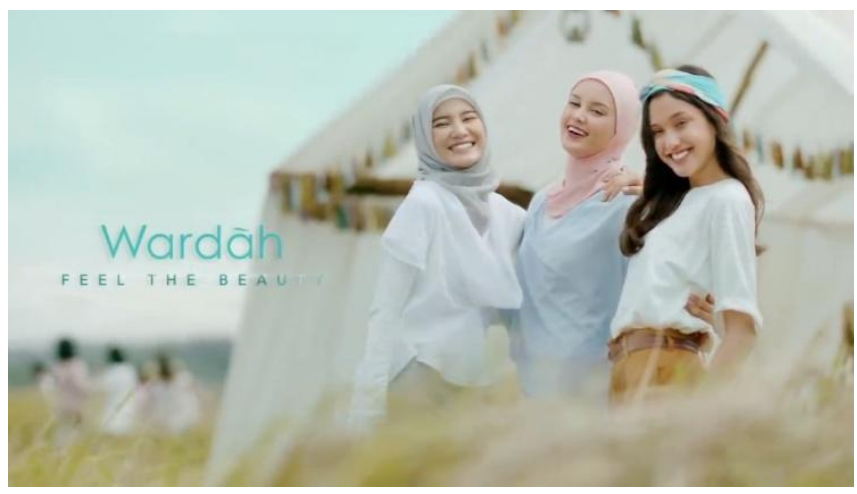

Gambar 1. Adegan Terakhir Iklan Wardah versi Feel The Beauty

Salah satu adegan terakhir dalam Iklan Wardah. Scene dalam denotasi, ketiga perempuan yang terlihat bahagia melihat anak-anak yang sedang bercanda-tawa. Dalam scene tersebut terdapat narasi "Wardah feel the beauty". Maksud dari kalimat tersebut adalah sebuah tagline dari Wardah sekarang. Bahwa kecantikan itu dapat dirasakan.

Scene dalam konotasi, ketiga perempuan tersebut menampilkan bahwa kecantikan dapat dirasakan dengan kesenangan mereka. Mitos dalam scene tersebut, dengan menggunakan produk Wardah sudah dapat merasakan kecantikannya.

Iklan televisi Wardah versi Feel The Beauty menampilkan sebuah cerita tentang seorang perempuan yang sedang berbagi dengan lingkungannya. Adeganadegan yang dibuat dalam iklan memberikan pesan kepada perempuan bahwa kecantikan tidak hanya mempunyai kulit yang cerah, bibir yang indah, tangan yang terawat maupun yang dapat dilihat saja melainkan kecantikan yang dapat dirasakan oleh sekitar. Wardah juga mengajak bahwa perempuan dapat memberikan banyak inspirasi untuk memancarkan cantiknya perempuan yang sesungguhnya. 


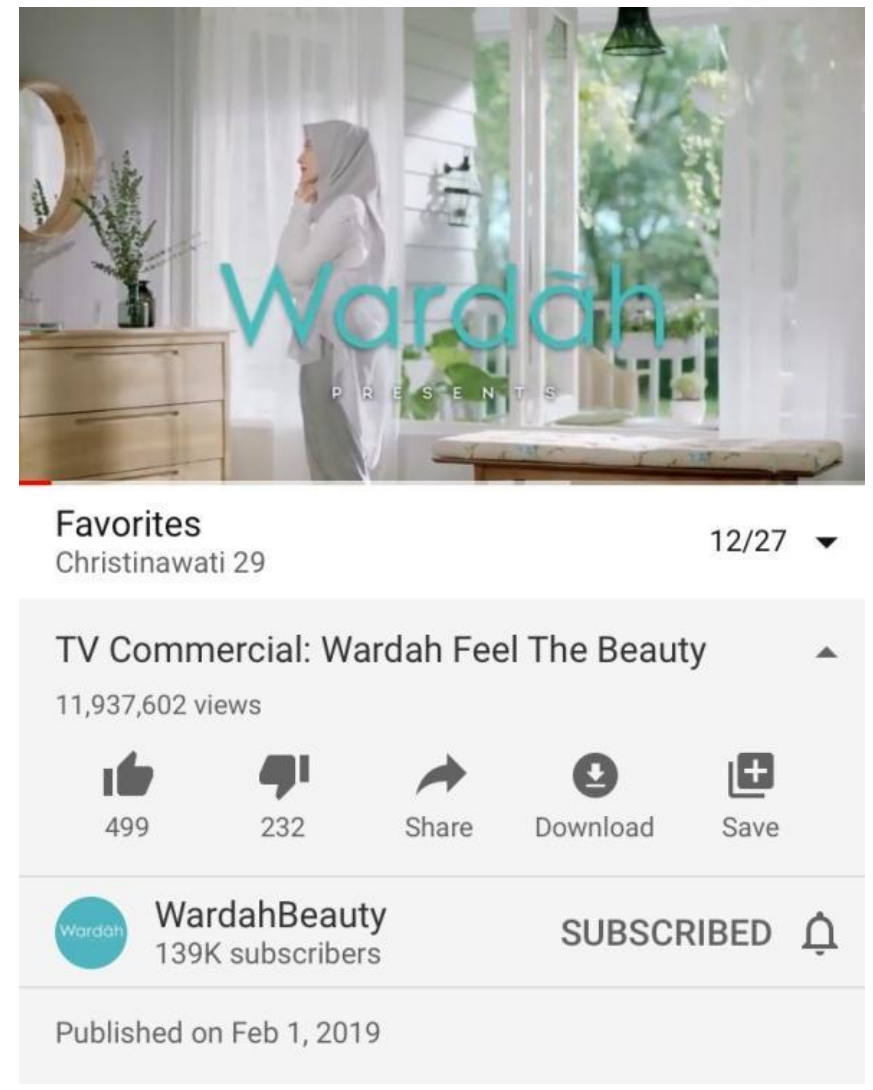

\section{Gambar 2. Iklan Wardah Feel The Beauty}

Dalam iklan tersebut perempuan yang cantik direpresentasikan sebagai perempuan yang tidak hanya cantik dari segi fisik melainkan dari dalam diri. Kecantikan yang diperoleh dari segi fisik yaitu penggunaan barang-barang yang dapat menambah nilai kecantikan, barang barang tersebut seperti produk kecantikan dari Wardah. Kecantikan dari dalam diri dapat dilihat dari inner beauty seorang perempuan.

Perempuan yang ada di dalam iklan tersebut tidak hanya perempuan yang mengenakan hijab saja tetapi perempuan yang tidak memakai hijab pun ada. Kecantikan yang digambarkan iklan Wardah tidak sebatas paras yang cantik dan sempurna. Dengan perempuan yang menggunakan hijab tidak kalah fashionable dengan yang tidak menggunakan hijab. Iklan Wardah pun membuktikan bahwa perempuan yang mengunakan hijab maupun tidak sama-sama mempunyai standar kecantikannya sendiri. Dengan berhijab pun tidak menutup kemungkinan untuk dapat terlihat cantik dalam segi fisik. Perempuan yang cantik tidak hanya ditujukan kepada perempuan yang memiliki wajah yang sempurna seperti kulit yang putih mulus, memiliki hidung yang mancung atau perempuan cantik yang menggunakan make up. Kecantikan perempuan dapat juga dilihat dari dalam dirinya, yaitu kecantikan yang berasal dari pancaran hati seperti kebaikan, kelembutan, dan juga kepintaran. Dari sebuah penelitian yang dilakukan citra kecantikan perempuan di media massa dapat memberikan perasaan negatif pada perempuan terhadap fisik mereka yang merasa kurang nyaman karena adanya perbedaan atau kurang ideal pada tubuh mereka ataupun merasa kekurangan dalam fisik. Kepercayaan diri perempuan tidak muncul dengan sendirinya, banyak perempuan yang masih merasa ketakutan karena perempuan itu sendiri menganggap bahwa kecantikannya tidak maksimal. Banyak 
perempuan melakukan untuk meningkatkan kepercayaan dirinya dengan merias wajah mereka.

Iklan Wardah ini tidak hanya menjual produk melainkan menjual sebuah citra kecantikan yang ditampilkan. Citra yang ditampilkan dalam iklan Wardah adalah kecantikan fisik dan juga kecantikan dari hati perempuan itu sendiri. Hal tersebut dapat mempengaruhi pandangan masyarakat tentang definisi kecantikan. Penampilan yang sempurna bagi perempuan akan dirasakan ketika penampilan fisik dengan memiliki kepercayaan diri dan dari dalam diri disatu padukan maka itulah arti kecantikan yang sesungguhnya.

Kecantikan dalam iklan tersebut juga mengingatkan bahwa dengan kecantikan yang kita miliki melalui kepercayaan diri dan memiliki inner beauty yang baik dan tulus maka dapat terpancarkan kecantikan kita dengan sendirinya tanpa harus menutupi kekurangan dan merasa berbeda. Berbagi dari hal yang kecil seperti senyuman saja sudah dapat memberikan pandangan kecantikan itu sendiri.Berawal dari keinginan tampil lebih cantik, maka banyak perempuan yang membeli produk kosmetik mulai dari perawatan wajah, tubuh hingga make up untuk mengurangi kekurangan yang ada di wajah. Iklan televisi kosmetik Wardah versi Feel The Beauty memiliki daya tarik dan tujuan tersendiri. Oleh karena itu, peneliti berpendapat bahwa iklan ini sebagai bentuk dari pencitraan dan persuasif dari produk Wardah itu sendiri.

\section{Simpulan}

Konsep kecantikan perempuan terutama perempuan berhijab dan pemaknaan tanda dalam iklan televisi khususnya iklan Wardah versi Feel The Beauty, Kecantikan menurut iklan tersebut adalah kecantikan yang didapat bukan hanya dari luar yaitu fisik melainkan dari dalam diri. Dengan memiliki hati yang baik maka kecantikan dapat sempurna saat disatu padukan dengan kepercayaan dirinya yang tidak merasa berbeda dengan adanya standar kecantikan selama ini yang harus terlihat kulit putih bersih dan mulus, memiliki hidung mancung maupun tinggi dan kurus. Pemaknaan tanda yang diberikan dalam iklan memberikan gambaran bahwa kita cantik dengan kepercayaan diri kita, dengan kebaikan kita dan jangan lupa untuk berbagi dalam menginspirasi banyak orang dengan kebaikannya agar kecantikan dapat terpancarkan dengan sendirinya. Kecantikan fisik seorang perempuan tidak dapat diukur hanya melalui fisik karena kecantikan seorang perempuan itu berbeda-beda. Fisik bukanlah patokannya, dengan memiliki fisik yang hampir sempurna atau yang disukai banyak perempuan lainnya tetapi tidak di seimbangkan dengan inner beauty atau attitude bagi penulis kecantikan seperti itu belum sempurna. Kecantikan yang sempurna ataupun arti kecantikan bagi penulis yaitu ketika kecantikan fisik dan inner beauty menjadi satu.

\section{Ucapan Terima Kasih}

Terimakasih kepada orang-orang yang telah membantu untuk penelitian ini dari awal hingga terakhir. Terutama kepada narasumber yang sudah membantu untuk terlibat dalam penelitian ini. 


\section{Daftar Pustaka}

Bungin, Burhan. (2013). Konstruksi Sosial Media Massa: Kekuatan Pengaruh Media Massa, Iklan Televisi, dan Keputusan Konsumen Serta Kritik Terhadap Peter L. Berger \& Thomas Luckmann. Jakarta: Kencana.

Dewi, Murti Candra. (2013). Representasi Pakaian Muslimah Dalam Iklan (Analisis Semiotika Charles Sanders Peirce pada Iklan Kosmetik Wardah di Tabloid Nova). Jurnal Komunikasi Profetik, 6 (2). Diakses dari :http://ejournal.uinsuka.ac.id/isoshum/profetik/article/download/1171/1081.

Djamerang, Asmi. (2018). Analisis Semiotika Pada Iklan di Televisi. Jurnal AlKhitabah, 6 (1), 1-16. Diakses dari: http://journal.uinalauddin.ac.id/index.php/Al-Khitabah/article/download/4713/4260.

Effendi, Irfan. (2016). Kecantikan Has Wanita Berjilbab dalam Iklan Televisi (Analisis Semiotika Terhadap Iklan Kosmetik Wardah Versi Kisah di Balik Cantik). Skripsi. Tidak Diterbitkan. Fakultas Dakwah dan Komunikasi. Universitas Islam Negeri Alauddin: Makassar. Diakses dari: http://repositori.uinalauddin.ac.id/4500/1/IRFAN\%20EFENDI\%20\%2850500 112005\%29.PDF

Enzim. (2012). Analisis Data Metodologi Penelitian Kualitatif. Jakarta: Rajawali Pers Jefkins, Frank. (1997). Periklanan. Jakarta: Erlangga

Melliana, Annastasia S. (2006). Perempuan dan Mitos Kecantikan. Yogyakarta: PT. IKis Pelangi Aksara

Moleong, Lexy J. (2009). Metodologi Penelitian Kualitatif. Bandung: PT. Remaja Rosdakarya

Moleong, Lexy J. (2013). Metodologi Penelitian Kualitatif. Bandung: PT. Remaja Rosdakarya.

Sahara, Anisa Rohmah. (2019). Reprsentasi Cantik Iklan Wardah di Televisi (Studi Analisis Semiotik Iklan Wardah Exclusive Series Versi Dewi Sandra In Paris). Skripsi. Tidak Diterbitkan. Fakultas Ushuluddin Adab dan Dakwah. Institut Agama Islam (IAIN): Ponorogo. Diakses dari: http://etheses.iainponorogo.ac.id/5835/1/FIX.pdf

Sari, Wulan Purnama. (2017). Konflik Budaya Dalam Konstruksi Kecantikan Wanita Indonesia (Analisis Semiotika dan Marxist Iklan Pond's White Beauty versi Gita Gutawa). Jurnal Komunikasi, 2, 7

Sobur, Alex. (2012). Semiotika Komunikasi. Bandung: PT. Remaja Rosdakarya.

Williams, Raymond.(2009). Televisi. Yogyakarta: Resist Book

Wolf, N. (2004). Beauty Myths: How Images of Beauty Used Against Women. New York: Morrow

Worotitjan, Hulda Grace. (2014). Konstruksi Kecantikan dalam Iklan Kosmetik Wardah. Jurnal e-komunikasi. 2 (2). Diakses dari: http://publication.petra.ac.id/index.php/ilmukomunikasi/article/download/1787/1636. 